\title{
Infections and risk of Type I (insulin-dependent) diabetes mellitus in Lithuanian children
}

\author{
A.Pundziūtè-Lyckå ${ }^{1}$, B. Urbonaite $\dot{e}^{2}$, G. Dahlquist ${ }^{1}$ \\ ${ }^{1}$ Department of Clinical Sciences, Paediatrics, Umeå University, Umeå, Sweden \\ ${ }^{2}$ Institute of Endocrinology, Kaunas Medical University, Kaunas, Lithuania
}

\section{Abstract}

Aims/hypothesis. The role of infections in the aetiology of Type I diabetes is controversial. Certain enteroviral infections might be involved in triggering the beta-cell destruction but insufficient exposure to early infections might increase the risk. We studied how the number of infections experienced during several periods from birth to onset influence diabetes risk.

Methods. The study group came from the five largest Lithuanian cities: 124 patients, selected from the 0-14 years-of-age childhood diabetes register and 372 population-based control subjects matched with them for age group and sex. Information about infections and duration of breastfeeding was collected from health care booklets, other data from a mailed questionnaire, returned by $94.4 \%$ of patients and $72.6 \%$ of control subjects.

Results. One or more infections experienced during the first half year of life tended to reduce diabetes risk. Crude odds ratios (95\% confidence intervals) in the $0-14,0-4$ and 5-14 years-of-age groups were $0.66(0.42-1.04), 1.06(0.48-2.36)$ and 0.52 $(0.30-0.90)$ respectively. Adjustment for the duration of breastfeeding, number of people in the household, duration of mother's education and birth order of the index child made little difference. Odds ratios $(95 \%$ confidence intervals) in the $0-14,0-4$ and 5-14 years-of-age groups were 0.60 (0.37-0.98), 0.94 (0.40-2.20) and $0.47(0.26-0.87)$, respectively. The number of infections recorded during the last preonset year or from birth to onset did not influence diabetes risk.

Conclusion/interpretation. Exposure to infections early in life could decrease diabetes risk, particularly for children diagnosed after the age of 4 years. [Diabetologia (2000) 43: 1229-1234]

Keywords Type I (insulin-dependent) diabetes mellitus, case control study, infections, risk factors, childhood.
Infections caused by several different viruses are associated with Type I (insulin-dependent) diabetes mellitus in experiments with animal models, case reports and seroepidemiological studies in humans [1, 2]. Certain viruses are able to cause direct cytolysis or trigger the autoimmunity against the beta cells by different mechanisms [1]. Viral infections could be

Received: 1 March 2000

and in revised form: 13 June 2000

Corresponding author: A. Pundziūtè-Lyckå, Department of Clinical Sciences, Paediatrics, Umeå University, 90185 Umeå, Sweden the initiating, accelerating and/or precipitating events in the pathogenesis of Type I diabetes [3, 2]. Infections caused by rubella $[4,5]$, Coxsackie B group and echoviruses might induce beta cell damage in genetically susceptible children if experienced during fetal life [6-8]. Even later in childhood enteroviral infections have been temporary associated with islet cell antibody seroconversion [8,9]. Compared with control groups, diabetic children experience non-specific infections more often during the last year before diabetes onset [10-13]. Infections could precipitate the on-going beta-cell destruction and unmask the already existing insulin deficiency by increasing insulin need during an acute inflammation. Increased con- 
centrations of circulating cytokine IL-1 during episodes of common infections could also cause betacell damage and antigen release or increase beta-cell susceptibility to immunological damage [14].

There is some evidence from animal experiments and indirect epidemiological associations in humans, suggesting that lack of immune stimulation due to insufficient exposure to infections early in life might increase the risk of getting diabetes. In genetically predisposed animals the frequency of diabetes increases if they are raised in pathogen-free environments $[15$, 16]. Certain viral infections [17-19] or immune stimulation with bacterial antigens early in life reduce diabetes incidence in these animals [20-22]. Globally the highest and increasing incidence of insulin-dependent diabetes is observed in the affluent countries [23, 24]. A strong inverse correlation between total and childhood population density and incidence of Type I diabetes was shown in Finland [25]. In Northern Ireland the incidence of insulin-dependent diabetes is lowest in areas with highest population density and most household crowding [26]. A few case control studies from different countries have observed that diabetes risk is increased in children from higher socio-economic class families [27-29] and decreased in those living in overcrowded households [27] although the evidence is conflicting $[12,13,30]$. These observations led to formulation of the 'hygiene' hypothesis [31]. A study based on prospective records in health care booklets showed that exposure to common childhood infections during the first year of life reduces diabetes risk [32]. In a study based on more material from structured questionnaires the protective effect was, however, statistically non-significant [10].

The relation between short duration of total breastfeeding and early exposure to cows' milk proteins with increased risk of Type I diabetes has been shown by a number of studies in humans [33] and in animal models [34, 35]. Duration of breastfeeding also modulates, however, the incidence and prevalence of infections early in life. Acute respiratory infections, diarrhoea [36] and otitis media [37] are known to be lower in fully breastfed compared with formula-fed infants.

In our case control study, based on prospective records in health care booklets of Lithuanian children, we investigated whether the risk of insulin-dependent diabetes is influenced by the number of infections experienced during the first half year of life, the last pre-onset year, and from birth until the onset of diabetes.

\section{Subjects and methods}

Since 1983 the nation-wide Lithuanian register of childhood insulin-dependent diabetes prospectively registers all new patients below the age of 15 years at diagnosis [23, 38]. Details of the ascertainment procedure have been described previously [39]. Current study material was collected as an additional data set within a multicentre European study EURODIAB substudy 2 "Environmental determinants of insulin-dependent diabetes in childhood" [40]. The ethics committee of Kaunas Medical University approved the Lithuanian part of the study. Informed consent was obtained from the parents of study participants for checking medical documentation.

Patient group. The study group was selected from the Lithuanian register of childhood insulin-dependent diabetes according to the following criteria: (1) diabetes diagnosed from 1 January 1989 to 31 December 1994 (recruitment period), (2) diagnosis established before the fifteenth birthday, (3) resident in one of the five largest Lithuanian cities at the time of diagnosis, (4) born after 1 January 1980. There were 130 children who fulfilled the inclusion criteria. Of them 4 patients emigrated and 2 died before the data collection started leaving 124 children eligible for the study.

Control group. To form a population-based control group we used a two-stage sample selection procedure. In the Lithuanian health care system children below the age of 16 years were assigned a district paediatrician and a nurse depending on their address. Thus, district lists of paediatricians working at children polyclinics would include all children living in a certain area. Firstly, we selected 53 at random from 475 district paediatricians working in the five largest cities. Secondly, we selected three control children per patient at random from the district lists of selected paediatricians, in total 372 children. Control children were matched to the patients at group level for sex and birth year range. In the data analysis, the calendar midpoint of the patient recruitment period (1 January 1992) was used as the end of observation period for control children. Grouping into 0-4, 5-9 and 10-14 years of age by 1 January 1992 resulted in approximately three times as many control as diabetic children in corresponding age groups.

A questionnaire inquiring about a variety of early environmental exposures was prepared for the EURODIAB substudy 2 according to a common protocol. For the current study we added questions about the socioeconomic situation of the family at the time of the child's birth and the duration of the parents' education. In September 1995 questionnaires were mailed to all study participants. When questionnaires were not returned two reminder letters were sent or phone calls made or both to find the reason for non-response and increase the response rates. Incompletely or inaccurately filled questionnaires were completed by telephone interviews.

Parents of $94 \%$ of the eligible patients $(92 \%$ of girls and $97 \%$ of boys) and $73 \%$ of control subjects ( $78 \%$ of girls and $68 \%$ of boys) responded (Pearson Chi-squared $p=0.03$ for the control subjects). Distribution of the responding study participants in different age-at-diabetes-onset groups is presented in Table 1. The reasons of non-response in the control group were active refusal $17(4.6 \%)$, passive refusal (parents agreed to participate but did not return the questionnaire) $19(5.1 \%)$, not possible to trace $54(14.5 \%)$ and left study area 12 $(3.2 \%)$. In the patient group parents of $2(1.6 \%)$ children actively and $5(4.0 \%)$ passively refused to participate. There were no systematic differences between the responding and non-responding diabetic children in their age group and sex. The proportions of responding and non-responding control children, or boys and girls separately, did not differ in the age groups. In the 0-4 years-of-age group responding control children were younger than patients (Mann-Whitney test, twotailed $p=0.048)$. 
Table 1. Distribution of responding study participants in the age at onset groups by sex

\begin{tabular}{|c|c|c|c|c|c|c|}
\hline \multirow[t]{2}{*}{ Age (years) } & \multicolumn{2}{|c|}{ Boys $n(\%)$} & \multicolumn{2}{|l|}{ Girls $n(\%)$} & \multicolumn{2}{|c|}{ All children $n(\%)$} \\
\hline & Diabetic & Control & Diabetic & Control & Diabetic & Control \\
\hline $0-4$ & $21(33.9)$ & 45 (34.6) & $15(27.3)$ & $52(37.1)$ & $36(30.8)$ & $97(35.9)$ \\
\hline $10-14$ & $11(17.7)$ & $25(19.2)$ & $9(16.4)$ & $24(17.1)$ & $20(17.1)$ & $49(18.1)$ \\
\hline Total & $62(100.0)$ & $130(100.0)$ & $55(100.0)$ & $140(100.0)$ & $117(100.0)$ & $270(100.0)$ \\
\hline
\end{tabular}

Data from health care booklets. The health care authorities required the district paediatrician and nurse to do monthly health check-ups during the first year of life. Weight, height and notes about infant feeding were recorded in the health care booklets. Parents were encouraged to contact the physician even in the event of minor illnesses of their children. When requested by telephone, district physicians visited acutely ill children at home. Dates, clinical findings, diagnoses and prescribed treatments were recorded in the health care booklets, including hospital discharge information letters.

We traced the health care booklets of the responding study participants and collected the information about infectious diseases and feeding in infancy. Dates and categories of infectious diseases were entered into a database. For the data analysis we extracted the number of infections experienced during three periods of life: the first half-year, the last year before the onset and from birth until the onset of diabetes (or 1 January 1992 for the control subjects). The end of breastfeeding was estimated as the midpoint between the last record with breastfeeding and the first record without breastfeeding.

Statistical analysis. Variables were categorised using the percentile values estimated from the distributions of their values in patients and control subjects taken together. The number of early infections, the number of people in the household and the duration of the mother's education were categorised using the value of the $50^{\text {th }}$ centile and the duration of breastfeeding using the $25^{\text {th }}$ centile for the cut-off. The number of infections experienced from birth to diabetes onset was categorised separately in the $0-4$ and 5-14 years-of-age groups, using the value of the $50^{\text {th }}$ centile of the age group, because the number of infections differed considerably between the groups. Adjustment for the duration of follow-up in years was made when analysing the association between the total number of infections and diabetes risk.

Univariate analyses were done using the QUEST software, developed for the Swedish Medical Research Council by L. Gustafsson, University of Umeå, Sweden. Odds ratios and $95 \%$ confidence intervals were calculated according to Miettinen's method, significance of the association was checked using the chi-squared test. Linear trend in dose-response was analysed using the Mantel-Haenszel extension test. The homogeneity test was done to check if odds ratios in different age strata were equally large. Multivariate and descriptive analyses were done using the Statistical Package for Social Sciences (SPSS 7.5.1). Logistic regression analysis was used to adjust for potential confounders by forcing combinations of variables into the models. The significance level of the Wald statistic shows if the beta coefficient of an individual variable significantly differs from 0 .

\section{Results}

Number of infections during the first half-year of life. The results of univariate analyses are presented in Table 2. Exposure to at least one infection during the first 6 months of life tended to reduce the odds of getting diabetes $(p=0.07)$ in children $0-14$ years old. The association somewhat differed between the two age groups. Exposure to at least one early infection did not influence the risk of diabetes in the 0-4 years-of-age group but statistically significantly reduced it in the 5-14 years-of-age group. This difference was, however, not statistically significant (homogeneity test $p=0.14$ ). The number of infections experienced during the first half year of life was negatively associated with the duration of breastfeeding (Spearman $r=-0.22, p=0.02$ in patients, and $r=-0.21$, $p=0.001$ in control subjects). The number of infections experienced during the second half year of life was positively associated with the number of people in the household $(r=0.02, p=0.83$ in patients and $r=0.18, p=0.01$ in control subjects). The total duration of breastfeeding did not influence diabetes risk in itself. Notably, the association between diabetes risk and number of people in the household closely resembled the association seen between diabetes risk and the number of early infections (Table 2).

Table 3 shows the results obtained from logistic regression analysis, adjusting for duration of breastfeeding, number of people in the household, duration of the mother's education and birth order of the child. After adjustment for confounders, the odds of getting diabetes was reduced in children $0-14$ years old who were exposed to at least one early infection $(p=0.04)$. We did the analyses in the $0-4$ and 5-14 years-of-age groups, to check if the association differed depending on the age at diabetes onset. Adjustment for confounders hardly changed the crude results. No association was found in the $0-4$ years-ofage group $(p=0.88)$. In the 5-14 years-of-age group, after adjustment for confounders, the odds of getting diabetes remained significantly reduced if children were exposed to at least one early infection $(p=0.02)$.

Number of infections from birth until diabetes onset. There was no association between the total number of infections experienced from birth until diabetes 
Table 2. Crude odds ratios for exposure to early infections, duration of breastfeeding and household crowding

\begin{tabular}{|c|c|c|c|c|c|c|}
\hline Age at onset & Categories c & variable & $\begin{array}{l}\text { Patients } \\
n\end{array}$ & $\begin{array}{l}\text { Control } \\
\text { subjects } n\end{array}$ & OR (95\% CI) & $\begin{array}{l}\chi^{2} \text { test } \\
p \text { value }\end{array}$ \\
\hline & \multicolumn{5}{|c|}{ Number of infections during the first half year } & \\
\hline \multicolumn{7}{|c|}{ 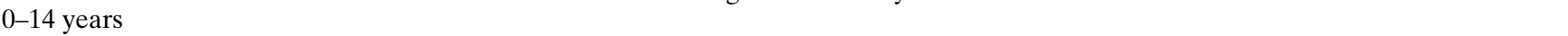 } \\
\hline Control subjects $n=248$ & Exposure: & $\geq 1$ infection & 52 & 145 & $0.66(0.42-1.04)$ & 0.07 \\
\hline \multicolumn{7}{|l|}{$0-4$ years } \\
\hline Patients $n=34$ & Reference: & No infection & 15 & 42 & $1.06(0.48-2.36)$ & 0.85 \\
\hline \multicolumn{7}{|l|}{$5-14$ years } \\
\hline Patients $n=74$ & Reference: & No infection & 41 & 61 & \multirow[t]{2}{*}{$0.52(0.30-0.90)$} & \multirow[t]{2}{*}{0.02} \\
\hline \multirow[t]{2}{*}{ Control subjects $n=156$} & Exposure: & $\geq 1$ infection & 33 & 95 & & \\
\hline & \multicolumn{5}{|c|}{ Duration of breastfeeding } & \\
\hline \multicolumn{7}{|l|}{$0-14$ years } \\
\hline Patients $n=111$ & Reference: & $\leq 7$ weeks & 30 & 62 & $0.88(0.53-1.46)$ & 0.62 \\
\hline \multicolumn{7}{|l|}{$5-14$ years } \\
\hline Patients $n=76$ & Reference: & $\leq 7$ weeks & 18 & 31 & \multirow{2}{*}{$0.78(0.40-1.51)$} & \multirow[t]{2}{*}{0.47} \\
\hline \multirow[t]{2}{*}{ Control subjects $n=159$} & Exposure: & $>7$ weeks & 58 & 128 & & \\
\hline & \multicolumn{5}{|c|}{ Number of people in the household } & \\
\hline \multicolumn{7}{|l|}{ 0-14 years } \\
\hline Patients $n=116$ & Reference: & $\leq 4$ people & 82 & 163 & \multirow[t]{2}{*}{$0.63(0.40-1.01)$} & \multirow[t]{2}{*}{0.05} \\
\hline Control subjects $n=270$ & Exposure: & $>4$ people & 34 & 107 & & \\
\hline \multicolumn{7}{|l|}{$0-4$ years } \\
\hline Patients $n=36$ & Reference: & $\leq 4$ people & 23 & 61 & \multirow[t]{2}{*}{$0.96(0.43-2.13)$} & \multirow[t]{2}{*}{0.88} \\
\hline Control subjects $n=97$ & Exposure: & $>4$ people & 13 & 36 & & \\
\hline
\end{tabular}

onset and the risk of getting diabetes in children $0-14$ years old $[\leq 12$ vs $>12$ infections OR 0.66 , $95 \%$ CI (0.39-1.11)]. The risk of diabetes tended to increase with increasing total load of infections in the $0-4$ years-of-age group $[\leq 5$ vs $>5$ infections OR $2.11,95 \%$ CI (0.84-5.31)] but this tendency was not statistically significant. No association was found in the 5-14 years-of-age group [ $\leq 17$ vs $>17$ infections OR 1.10, $95 \%$ CI (0.63-1.90)].

Number of infections during the last year before diabetes onset. There was no statistically significant effect on the risk of getting diabetes depending on the level of exposure to infections in the last year before diabetes onset. There was, however, a tendency for increased risk in the 0-4 years-of-age age group if the children were exposed to more infections $[\leq 2$ vs $>2$ infections OR 1.91, 95\% CI (0.87-4.17)].

\section{Discussion}

The results of the present study support the 'hygiene hypothesis' [31], suggesting that exposure to infec- tions early in life reduce the risk of diabetes. The results confirm previously reported studies from Southampton [32] and Sweden [10], which found that exposure to non-specific infections during the first year of life has an inverse association with childhood diabetes. The results of the Swedish study were statistically non-significant, but that could have been because of data imprecision because the study used parent questionnaire material. In contrast to an earlier report [32] the protective effect in our study was only pronounced for children who developed diabetes after the age of 4 years. Adjustment for possible confounders such as duration of breastfeeding and household crowding did not greatly change the crude estimates.

The strength of this population-based study is that it used prospectively recorded information from the health care booklets of study participants and thus should be free from the disease-dependent bias. Although the organisation of the child health care system in Lithuania during the study period promoted consultation of a physician even for minor infections of the infant, health care booklet records probably underestimate the true frequency of infections. Completeness of the records about infectious diseases is 
Table 3. Logistic regression analysis of the association between the exposure to infections during the first half year of life and diabetes risk, adjusted to potential confounders

\begin{tabular}{|c|c|c|c|c|}
\hline Age group & Exposure & OR $(95 \% \mathrm{CI})$ & $\begin{array}{l}\text { Beta } \\
\text { coefficient }\end{array}$ & $\begin{array}{l}p \text { value of } \\
\text { Wald statistic }\end{array}$ \\
\hline \multicolumn{5}{|l|}{$0-14$ years } \\
\hline Patients $n=99$ & $\geq 1$ infection $0-6$ months & $0.60(0.37-0.98)$ & -0.50 & 0.04 \\
\hline & $>4$ people in household & $0.78(0.47-1.28)$ & -0.25 & 0.32 \\
\hline & Education $>14$ years & $0.91(0.56-1.48)$ & -0.09 & 0.72 \\
\hline & Not $1^{\text {st }}$ child in the family & $1.14(0.70-1.85)$ & 0.13 & 0.59 \\
\hline \multirow[t]{4}{*}{ Control subjects $n=91$} & Breastfed $>7$ weeks & $1.05(0.42-2.61)$ & 0.05 & 0.92 \\
\hline & $>4$ people in household & $1.32(0.56-3.10)$ & 0.28 & 0.52 \\
\hline & Education $>14$ years & $0.64(0.27-1.52)$ & -0.44 & 0.32 \\
\hline & Not $1^{\text {st }}$ child in the family & $1.67(0.73-3.85)$ & 0.51 & 0.23 \\
\hline \multicolumn{5}{|l|}{ 5-14 years } \\
\hline Patients $n=68$ & $\geq 1$ infection $0-6$ months & $0.47(0.26-0.87)$ & -0.75 & 0.02 \\
\hline
\end{tabular}

also likely to decrease when children get older. It is, however, unlikely that record precision would systematically differ between diabetic and control children. Adjustment for the duration of the mother's education and birth order of the child (factors which could influence mother's decision to consult a physician for childhood infections, as well as the duration of breast feeding) did not change the estimates considerably.

The results of our study should be interpreted with caution because we have no information about the social class of the non-responding control children. The main reason for non-response among the control subjects was that they could not be traced $(14.5 \%)$. The majority of these families had no telephones in their apartments which probably indicates a lower social status, which in turn is likely to be associated with exposure to more infections. Thus, we think it is more probable that our results underestimate rather than overestimate the association.

The current study did not show a dose-response relation of the association where the risk of getting diabetes would decrease in parallel to an increasing number of early infections. We found that exposure to at least one infection during the first half year of life was negatively associated with diabetes, possibly suggesting that it is the timing of the first infection that matters. This contradicts a recent observation that neonatal infections are associated with an increased risk of diabetes [41]. Although neonatal infections constitute only a fraction of infections experienced during the first 6 months, most of the severe infections happen in the neonatal period. Severe infections that happen very early in life might have different consequences than milder infections experienced later.
It is also possible that children who get infections relatively early in life live in conditions that also favour exposure to more infections later in infancy. Thus the negative association observed in children 5-14 years old could support the hypothesis that input deprivation syndromes are relevant in the development of the immune system [42]. In this study, which is based on records of clinical diagnoses it is not possible to distinguish between the potentially diabetogenic and non-diabetogenic infections. We do not know if the initial injury to the beta cells occurred during the fetal period of life. Lack of negative association in the 0-4 years-of-age group might depend on the possibility that in a larger proportion of the children in this group the autoimmune process had been initiated during the fetal period of life or they experienced early infections that were diabetogenic.

The current study found no association between the degree of exposure to the total load of infections experienced from birth to diabetes onset or during the last pre-onset year and the risk of getting diabetes. This could be the result of record imprecision in the health care booklets, especially in the older children, because $25 \%$ of the children in the $0-4$ yearsof-age group compared with $41 \%$ in the 5-14 yearsof-age group had no infections recorded during the last pre-onset year.

Our case control study, based on prospective records in health care booklets of Lithuanian children, found a negative association between exposure to infections during the first half-year of life and subsequent diabetes.

Acknowledgements. This study is part of the EURODIAB ACE study granted by the Biomed I and II programmes from 
the European Union. Grants from the Swedish Medical Research Council, project no 07531 and the Swedish Diabetes Association were also supplied.

\section{References}

1. Szopa TM, Titchener PA, Portwood ND, Taylor KW (1993) Diabetes mellitus due to viruses - some recent developments. Diabetologia 36: 687-695

2. Rewers M, Atkinson M (1995) The possible role of enteroviruses in diabetes mellitus. In: Rotbart AH (ed) Human Enterovirus Infections. ASM Press, Washington, pp 353-374

3. Dahlquist GG (1997) Viruses and other perinatal exposures as initiating events for beta-cell destruction. Ann Med 29: 413-417

4. Menser MA, Forrest JM, Bransby RD (1978) Rubella infection and diabetes mellitus. Lancet i: 57-60

5. Rubinstein P, Walker ME, Fedun B, Witt ME, Cooper LZ, Ginsberg Fellner F (1982) The HLA system in congenital rubella patients with and without diabetes. Diabetes 31: 1088-1091

6. Dahlquist GG, Ivarsson S, Lindberg B, Forsgren M (1995) Maternal enteroviral infection during pregnancy as a risk factor for childhood IDDM. A population-based case-control study. Diabetes 44: 408-413

7. Dahlquist G, Frisk G, Ivarsson SA, Svanberg L, Forsgren M, Diderholm H (1995) Indications that maternal coxsackie B virus infection during pregnancy is a risk factor for childhood-onset IDDM. Diabetologia 38: 1371-1373

8. Hyoty H, Hiltunen M, Knip M et al. (1995) A prospective study of the role of coxsackie $\mathrm{B}$ and other enterovirus infections in the pathogenesis of IDDM. Childhood Diabetes in Finland (DiMe) Study Group. Diabetes 44: 652-657

9. Hiltunen M, Hyoty H, Knip M et al. (1997) Islet cell antibody seroconversion in children is temporally associated with enterovirus infections. Childhood Diabetes in Finland (DiMe) Study Group. J Infect Dis 175: 554-560

10. Blom L, Nystrom L, Dahlquist G (1991) The Swedish childhood diabetes study. Vaccinations and infections as risk determinants for diabetes in childhood. Diabetologia 34: 176-181

11. Soltesz G, Jeges S, Dahlquist G (1994) Non-genetic risk determinants for type 1 (insulin-dependent) diabetes mellitus in childhood. Hungarian Childhood Diabetes Epidemiology Study Group. Acta Paediatr 83: 730-735

12. Verge CF, Howard NJ, Irwig L, Simpson JM, Mackerras D, Silink M (1994) Environmental factors in childhood IDDM. A population-based, case-control study. Diabetes Care 17: 1381-1389

13. Siemiatycki J, Colle E, Campbell S, Dewar RA, Belmonte MM (1989) Case-control study of IDDM. Diabetes Care 12: 209-216

14. Mandrup Poulsen T (1996) The role of interleukin-1 in the pathogenesis of IDDM. Diabetologia 39: 1005-1029

15. Like AA, Guberski DL, Butler L (1991) Influence of environmental viral agents on frequency and tempo of diabetes mellitus in BB/Wor rats. Diabetes 40: 259-262

16. Wilberz S, Partke HJ, Dagnaes Hansen F, Herberg L (1991) Persistent MHV (mouse hepatitis virus) infection reduces the incidence of diabetes mellitus in non-obese diabetic mice. Diabetologia 34: 2-5

17. Oldstone MB (1990) Viruses as therapeutic agents. I. Treatment of nonobese insulin-dependent diabetes mice with virus prevents insulin-dependent diabetes mellitus while maintaining general immune competence. J Exp Med 171: 2077-2089

18. Schwimmbeck PL, Dyrberg T, Oldstone MB (1988) Abrogation of diabetes in BB rats by acute virus infection. Association of viral-lymphocyte interactions. J Immunol 140: 3394-3400

19. Dyrberg T, Schwimmbeck PL, Oldstone MB (1988) Inhibition of diabetes in BB rats by virus infection. J Clin Invest 81: 928-931

20. Shehadeh N, Calcinaro F, Bradley BJ, Bruchlim I, Vardi P, Lafferty KJ (1994) Effect of adjuvant therapy on development of diabetes in mouse and man. Lancet 343: 706-707
21. Sadelain MW, Qin HY, Sumoski W, Parfrey N, Singh B, Rabinovitch A (1990) Prevention of diabetes in the BB rat by early immunotherapy using Freund's adjuvant. J Autoimmun 3: 671-680

22. McInerney MF, Pek SB, Thomas DW (1991) Prevention of insulitis and diabetes onset by treatment with complete Freund's adjuvant in NOD mice. Diabetes 40: 715-725

23. Karvonen M, Tuomilehto J, Libman I, LaPorte R (1993) A review of the recent epidemiological data on the worldwide incidence of Type I (insulin-dependent) diabetes mellitus. World Health Organization DIAMOND Project Group. Diabetologia 36: 883-892

24. EURODIAB ACE Study Group (2000) Variation and trends in incidence of childhood diabetes in Europe. Lancet 355: 873-876

25. Karvonen M, Rusanen J, Sundberg M et al. (1997) Regional differences in the incidence of insulin-dependent diabetes mellitus among children in Finland from 1987 to 1991. Childhood Diabetes in Finland (DiMe) Study Group. Ann Med 29: 297-304

26. Patterson CC, Carson DJ, Hadden DR (1996) Epidemiology of childhood IDDM in Northern Ireland 1989-1994: low incidence in areas with highest population density and most household crowding. Northern Ireland Diabetes Study Group. Diabetologia 39: 1063-1069

27. Patterson CC, Carson DJ, Hadden DR, Waugh NR, Cole SK (1994) A case-control investigation of perinatal risk factors for childhood IDDM in Northern Ireland and Scotland. Diabetes Care 17: 376-381

28. Siemiatycki J, Colle E, Campbell S, Dewar R, Aubert D, Belmonte MM (1988) Incidence of IDDM in Montreal by ethnic group and by social class and comparisons with ethnic groups living elsewhere. Diabetes 37: 1096-1102

29. Metcalfe MA, Baum JD (1992) Family characteristics and insulin dependent diabetes. Arch Dis Child 67: 731-736

30. Blom L, Dahlquist G, Nystrom L, Sandstrom A, Wall S (1989) The Swedish childhood diabetes study - social and perinatal determinants for diabetes in childhood. Diabetologia 32: 7-13

31. Kolb H, Elliott RB (1994) Increasing incidence of IDDM a consequence of improved hygiene? Diabetologia 37: 729

32. Gibbon C, Smith T, Egger P, Betts P, Phillips D (1997) Early infection and subsequent insulin dependent diabetes. Arch Dis Child 77: 384-385

33. Gerstein HC (1994) Cow's milk exposure and type I diabetes mellitus. A critical overview of the clinical literature. Diabetes Care 17: 13-19

34. Elliott RB, Reddy SN, Bibby NJ, Kida K (1988) Dietary prevention of diabetes in the non-obese diabetic mouse. Diabetologia 31: $62-64$

35. Elliott RB, Martin JM (1984) Dietary protein: a trigger of insulin-dependent diabetes in the BB rat? Diabetologia 26: 297-299

36. Lopez-Alarcon M, Villalpando S, Fajardo A (1997) Breast-feeding lowers the frequency and duration of acute respiratory infection and diarrhea in infants under six months of age. J Nutr 127: 436-443

37. Dewey KG, Heinig MJ, Nommsen Rivers LA (1995) Differences in morbidity between breast-fed and formula-fed infants. J Pediatr 126: 696-702

38. Grabauskas V, Urbonaite B, Padaiga Z (1991) Incidence of childhood insulin-dependent diabetes mellitus in Lithuania 1983-1988. Acta Paediatr Scand 80: 718-719

39. Padaiga Z, Tuomilehto J, Karvonen M et al. (1997) Incidence trends in childhood onset IDDM in four countries around the Baltic sea during 1983-1992. Diabetologia 40: 187-192

40. The EURODIAB Substudy 2 Study Group (1999) Vitamin D supplement in early childhood and risk for Type I (insulin-dependent) diabetes mellitus. Diabetologia 42: 51-54

41. The EURODIAB Substudy 2 Study Group (2000) Infections and vaccinations as risk factors for childhood Type I (insulin-dependent) diabetes mellitus: a multicenre case-control investigation. Diabetologia 43: 47-53

42. Rook GA, Stanford JL (1998) Give us this day our daily germs. Immunol Today 19: 113-116 